\title{
FURTHER STUDIES ON ARTIFICIAL PARTHENOCARPY ${ }^{1}$
}

\section{Felix G. Gustafson}

IN THIs study on induced parthenocarpy the writer has had two objects in mind: to test out new compounds and to obtain further information on the mechanism of fruit development. The following new compounds have been used: 9,10-di-n-propyl-9,10dihydroxy -9,10-dihydro-1,2,5,6-dibenzanthracene and its potassium salt; 9-phenanthrylacetic acid and its potassium salt; theelin (oestrone); methylcholanthrene; Skatol; crude oestrin from pregnancy urine; 1,2,5,6-dibenzanthracene; N-methyl-pyrrole-2,5-dipropionic acid; pyrrole- $x$-acetic acid; pyrrole- $x$-carboxylic acid; and the potassium indole acetate.

These compounds were chosen for various reasons. Some were chosen because they have shown oestrogenic properties, others because of carcenogenic activities, others because they have been reported to cause growth in plants, while still others were chosen because it was thought there might be a correlation between inolecular structure and effectiveness in stimulating fruit development. The first four compounds were synthesized by Prof. Bachmann, and the pyrrole compounds were made by Mr. Safir, under the direction of Prof. Blicke, all of the Chemistry Department at the University of Michigan. The potassium indole acetate was made from indole acetic acid bought from Eastman Kodak Company. At the time the potassium indole acetate was made and used in experiments with tobacco, there was no published record of it having been used as a growth hormone, but since then Avery, Burkholder, and Creighton (1937) and also Zimmerman and Hitcheock (1937) have published on its growth activity. It should, however, be remembered that salts have previously been supplied to plants in buffered growth substance solutions, and in 1935 Thimann used the sodium salts of indole-, indene-, and cumaryl-acetic acids. The pyrrole compounds have not been used heretofore as growthpromoting substances. Their synthesis is exceedingly difficult.

In examining the structure of the compounds that have been found to be active, it occurred to the writer that the pyrrole group might be the active radicle in the indole compounds. Pyrrole acetic, -propionic, and -butyric acids were not available

1 Received for publication December 17, 1937.

The writer takes this opportunity of expressing his thanks to Prof. W. E. Bachman and to Dr. J. Bradbury for the chemicals they supplied, to Prof. F. F. Blicke for supervising the synthesis of the pyrrole compounds, to Mr. Safir for synthesizing the pyrrole compounds, and to $\mathrm{Mr}$. H. Dunham for assistance during the course of the investigation. This research has been aided by a grant from the Horace $H$. Rackham Trust Fund of the University of Michigan. commercially, and the question arose as to how to obtain them. On inquiry it developed that Prof. Blicke had synthesized pyrrole, and he consented to supervise the synthesis of compounds containing the pyrrole ring. Unsuccessful attempts were made to synthesize pyrrole mono-propionic acid, and the best that could be done was the synthesis of N-methylpyrrole-2, 5-dipropionic acid. Pyrrole- $\alpha$-acetic acid was very difficult to make, and only after several attempts was success attained. The beta compound has so far been unattainable.

During the winter greenhouse-grown plants were used, while in the summer the plants were grown in the field. The chemical was applied as a lanolin paste as in previous experiments (Gustafson, 1936) or injected into the ovary according to the method used by Yasuda (1934). Controls were run with and without pure lanolin or injection with distilled water.

REsucts.- Seven of these compounds used in concentrations designated within the brackets following the name were without any influence on the ovaries: theelin ( 0.6 per cent in lanolin); methyl-cholanthrene (5 per cent in lanolin); 1,2,5,6-dibenzanthracene (5 per cent in lanolin); N-methyl-pyrrole-2,5-dipropinoic acid ( 5 per cent in lanolin); 9,10-di-n-propyl-9,10dihydroxy -9,10-dihydro-1,2-5,6-dibenzanthracene (1 per cent in lanolin) and its potassium salt (0.2 per cent aqueous solution); and the potassium salt of 9-phenanthracene (about 0.1 per cent in lanolin). Oestrin, Skatol, and 9-phenanthrylacetic acid caused some growth of the ovaries of several flowers. Oestrin produced fruits in Salpiglossus that were from $1 / 5$ to $1 / 4$ normal size; 9-phenanthrylacetic acid $(0.2$ per cent aqueous solution) caused some development in Godetia and Clarkia; while Skatol (0.5 per cent in lanolin) caused a very slight but unmistakable growth in Matthiola. All the compounds used in concentrations of one or less per cent are very insoluble, and if higher concentrations had been used, the compounds would not have gone into solution.

Of the thirteen new compounds used only three were definitely successful: the Pyrrole- $\boldsymbol{\alpha}$-carboxylic, pyrrole- $x$-acetic acids, and the Potassium indole acetate. The last named was by far the best, and, while no quantitative experiments have been conducted, the potassium salt of indole acetic acid seems to be as effective as the acid itself, if not more so.

Potassium indole acetate.- The $\mathrm{K}$-indole acetate was the first of the three compounds to be used. In the greenhouse it was used on Clarkia elegans, Salpiglossus variabilis, Godetia sp., snapdragon, tomato, Maryland mammoth variety of tobacco, and cucumber. In the field, apple, pepper and eggplant flowers were treated with this compound. The $\mathrm{K}$-indole 


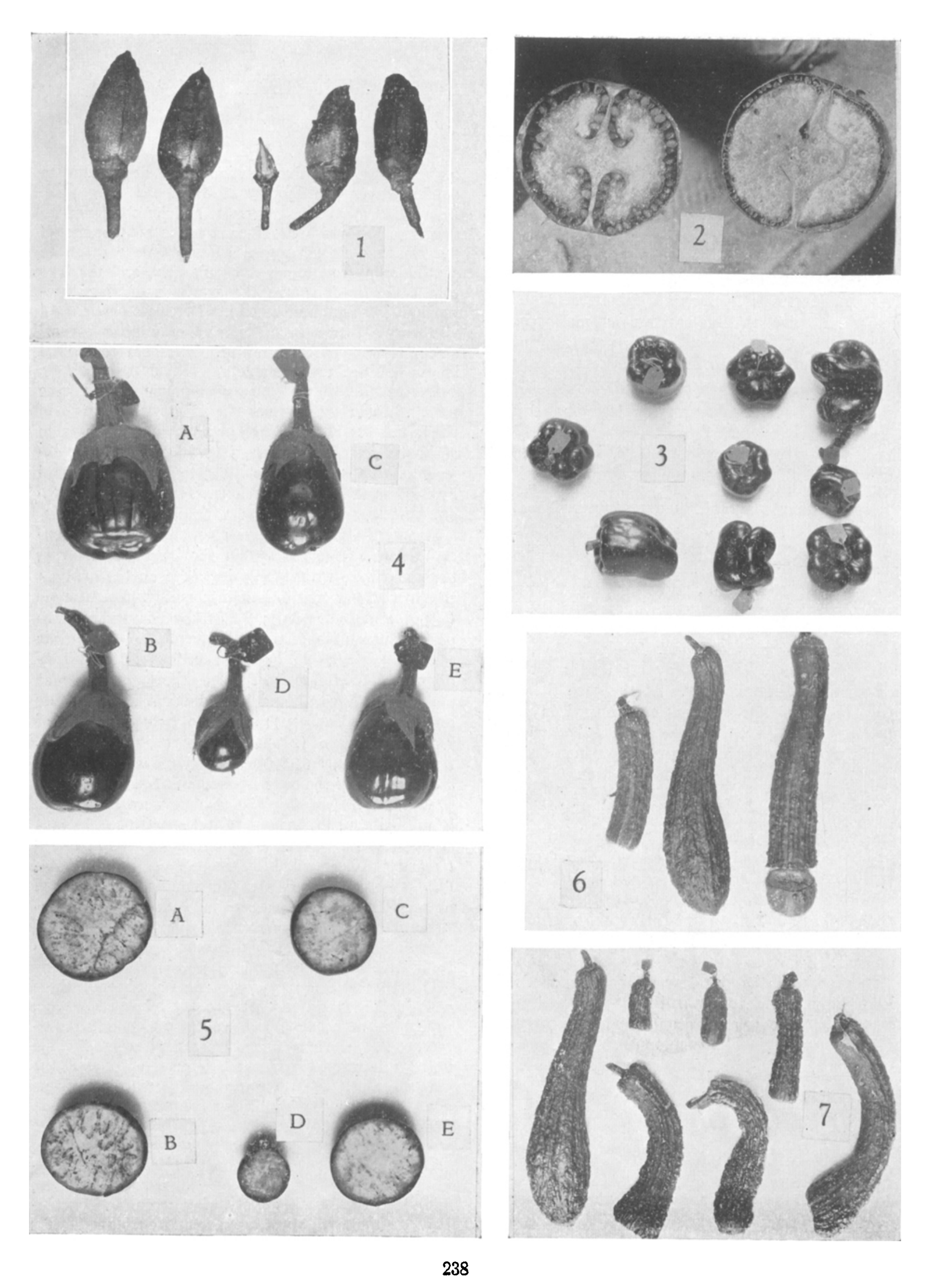


acetate was used either as a 5 per cent paste in lanolin or as a 0.2 per cent aqueous solution and injected. In all but the apple it produced an enlargement of the ovary.

Clarkia, Salpiglossus, Godetia, and snapdragon were treated only with the paste. The fruits produced on these plants were from one-half to normal size. The tobacco was both injected and treated with the paste. The latter produced considerable growth but never a normal sized or shaped fruit. The injection into the ovary was made through the pedicel with an ordinary syringe, using the finest obtainable needle. The needle was inserted into the pedicel, pushed into the ovary, and then withdrawn slightly before pressure was applied to the plunger. This procedure prevented clogging of the needle. Injection was continued until the air spaces in the sepals were filled with liquid, a condition which was easily observable. Sometimes the needle was accidentally pushed clear through the ovary, but when it was withdrawn, the ovary and the sepals were nevertheless completely injected.

Figures 1 and 2 picture the results obtained with the tobacco. On the left are the fruits obtained by pollination, in the midclle of figure 1 is the ovary, and on the right of both figures are the fruits produced by injecting the ovary with $\mathrm{K}$-indole acetate. The artificially produced fruits were usually somewhat smaller, and the tip was more often bent and somewhat shrivelled, showing signs of less complete development than the fruits produced by pollination. The ovules grew considerably and looked somewhat like small seeds, but from the large number that were placed to germinate not one seedling was obtained. Developing ovules were sectioned, but no traces of an embryo were noted, though in some instances there seemed to be an increase in the thickness of either the nucellus or the integuments, or both.

Of all the plants injected, the tobacco showed the greatest response. The ovary is not very large, but considerable liquid can be injected into it without damage, while the larger ovaries of the cucurbits are easily damaged, and ovaries of many plants are too small. The cucurbit ovaries are very turgid and crack easily, but the tobacco ovaries do not crack or split, which may be due to the presence of more intercellular spaces into which some of the liquid passes and from which it may later diffuse into the cells; the calyx, also, receives some of the injected liquid. It is perfectly possible that the growth substance injected into the calyx and the intercellular spaces of the ovary acts as a reserve which for some time continues to supply the growing cells. In some experiments several injections were made into the same ovary a few days apart. This was done to see if a larger and continued supply of the growth substance would produce a larger fruit, but the ovaries so treated did not grow any faster nor any larger than those receiving only one injection.

A considerable number of tomato ovaries were treated with 5 per cent $\mathrm{K}$-indole acetate paste, and some of these developed into ripe fruits without seeds. Some were of perfectly solid tissue with no trace of locules. However, most of the fruits had well developed locules, but no seeds. The fruits were essentially the same as those obtained with other growth compounds previously reported (Gustafson, 1936).

Cucumbers grown in the greenhouse were both injected and treated with paste. The ovaries injected did not grow into fruits. Sixteen ovaries were treated with the paste, and of these, three developed into mature fruits having an average diameter of $4.6 \mathrm{~cm}$. and a length of $8.33 \mathrm{~cm}$. No seeds or even enlarged ovules were found in these fruits, and the locules were very poorly developed. The thickness of the flesh was greater in these fruts than in those produced by pollination. It is well known that some varieties of cucumbers produce parthenocarpic fruits naturally, but not one of the controls in this variety showed the slightest sign of growth, to say nothing of growing into mature fruits. It might be mentioned in passing that a greater percentage of ovaries treated with 5 per cent indole acetic acid paste grew into fruits than of those treated with its salt, and the fruits were also somewhat larger.

Fig. 1-7,-Fig. 1. Tobacco. On the left are two fruits which were produced by pollination, in the middle is an ovary, and on the right are two fruits which were produced by injecting the ovaries with 1:500 K-indole acetate.Fig. 2. Tobacco. Cross section of the fruits shown in figure 1 . The section on the left is the normal fruit with seeds. The section on the right is the parthenocarpic fruit with partly developed ovules, but no seeds.-Fig. 3 . Peppers. The single fruit on the left was produced by treating the eut style with 5 per cent $\mathrm{K}$-indole acetate paste, the next two are normal fruits, and the six on the right were produced by treatment with 5 per cent indoleacetic acid paste.-Fig. 4. Egg plant. Fruits $A$ and $B$ are normal, $C$ is a parthenocarpic fruit produced by treatment with 5 per cent $\mathrm{K}$-indole acetate paste, $\mathrm{D}$ and $\mathrm{E}$ are parthenocarpic fruits produced by treatment with $\mathbf{5}$ per cent pyrrole- $\alpha$-carboxylic acid paste.-Fig. 5. Cross sections of the fruits in figure 4 . Notice the seeds in fruits A and $B$ and the lack of seeds in the others.-Fig. 6. Crookneck summer squash. The fruit on the left was produced by cutting off the apical end of an ovary in the flower bud stage, below the locules, leaving no ovules, and smearing the cut surface with 5 per cent indole butyric acid paste. The one in the middle is a normally produced fruit, while the fruit on the right was produced by cutting off the apical end of a young ovary, leaving some ovules, and smearing the cut surface with 5 per cent indole butyric acid paste.-Fig. 7. Crookneck summer squash. At the extreme left is a normal fruit. All the others were produced by cutting off the apical end of the ovary in the flower bud stage and smearing the cut surface with 5 per cent indole-butyric acid paste. The larger ones had more of the ovary left and some ovules. 
Peppers grown in the field were also treated with the paste of $\mathrm{K}$-indole acetate. It is well to note here the fact that the percentage of flowers that developed into fruits was usually smaller in the field than in the greenhouse. This was true of hand pollination as well as of other treatments. Of 61 flowers hand pollinated only 4 or 6.5 per cent grew into fruits. One hundred and ten flowers were treated with $\mathrm{K}$ indole acetate paste, and only 2 developed into fruits. This is only 1.9 per cent, and the fruits were somewhat shorter than the normally produced fruits, though the diameter was as great. In figure 3 the single fruit on the left was produced artificially by treatment with $\mathrm{K}$-indole acetate, the next two fruits were produced by pollination, and the six fruits on the right by treating the flowers with 5 per cent indole acetic acid paste. The parthenocarpic fruits had no seeds, and the placentae were greatly reduced. As a cross section figure of a parthenocarpic pepper has already been published by the author (Gustafson, 1937), it is not included here. In one of the fruits produced by the potassium salt and in several of those produced by the indole acetic acid, there were found a number of proliferations issuing from the placentae. These proliferations were about a centimeter in length, several appearing in each fruit. They have not been observed in any truits produced by pollination. It is an interesting fact that no flowers treated later than July 20 developed into fruits, and only one pollination after this date resulted in fruit setting. The majority of the $\mathrm{K}$-indole acetate treatments were made after this date, which may account for the low percentage of successes. However, natural setting must have occurred later than this date because at the time of the first frost there was an abundance of small fruits on the plants. No control ovaries of the pepper have ever been observed to develop into fruits or even to enlarge.

Only 10 flowers of field-grown egg plants were treated with K-indole acetate, and of these 3 grew into fruits without any seeds. The controls did not grow. Fruit C, in figures 4 and 5 was developed as a result of smearing the cut style with $\mathrm{K}$-indole acetate, while fruits $\mathrm{A}$ and $\mathrm{B}$ in the same figure are the results of hand pollinaton. Fruits $\mathrm{A}$ and $\mathrm{C}$ are of the same age. In fruits $\mathrm{A}$ and $\mathrm{B}$ the developing seeds are prominent, but no developing seeds are in evidence in fruit C. Further dissection failed to reveal any immature seeds. This dissection was necessary as these were not mature fruits and the seeds of the developing egg plants are not easily observed.

From the above illustrations it is obvious that the potassium salt of indole-acetic acid is active in inducing parthenocarpy -- perhaps not quite so active as the acid in most instances, but more active on tobacco.

Pyrrole- $\alpha$-carboxylic acid. - Of the pyrrole compounds synthesized the pyrrole- $\alpha$-carboxylic acid was the easiest to prepare, and it was the first one obtained. It was synthesized according to the method of McCay and Schmidt (1926). The melting point of the material used was $205^{\circ} \mathrm{C}$. This compound was used on pepper, tomato, egg plant, watermelon, crookneck summer squash, pumpkin, and tobacco. In only three species was there any evidence that this compound acted as a growth substance. Of 24 crookneck summer squashes treated 83.3 per cent showed some growth. The average in length of the ovary was only 59.0 per cent, but of the 15 controls only 33.3 per cent showed any increase, and the average increase of these amounted to only 26.0 per cent. While the increase in growth was very small, it seems that there was, nevertheless, a stimulating action. Ten flowers of eggplant were treated with a 5 per cent pyrrole- $\alpha$-carboxylic acid paste, and of these, 5 grew. Some were rather small at the time of picking, but that was due to the fact that they were very young. Fruits $\mathrm{D}$ and $\mathrm{E}$ in figures 4 and 5 are two of these fruits. Ninety-three tobacco ovaries were injected, and of these ovaries most remained attached to the plant for some time (if unpollinated, tobacco flowers drop off in two days). Eight ovaries remained on the plant for at least a month and more than doubled in size.

Though the results are not very striking, it seems to the author that one is justified in considering that pyrrole- $\alpha$-carboxylic acid possesses some growth promoting activity.

Pyrrole- $\alpha$-acetic acid. - This compound was the hardest to make and was obtained so late in the season that most of the plants were too old to be used. It was synthesized according to the method described by Nenitzescu and Solomonica (1931). The melting point of the material used was $84^{\circ} \mathrm{C}$. Egg plant, pepper, crookneck summer squash, and tobacco were treated with pyrrole- $\boldsymbol{\alpha}$-acetic acid. There was no growth in the pepper and only slight growth in the squash, which will be discussed in a later section. Twenty-five eggplant flowers were treated with a 5 per cent lanolin paste, and only 2 grew into fruits. One was $4 \mathrm{~cm}$. long, and the other was $7 \mathrm{~cm}$., when picked three weeks after treatment. This is not very large, but fruits produced by pollination that were a week older measured only 8 to $9 \mathrm{~cm}$. in length. One hundred and forty four tobacco ovaries were injected, and of these 10 per cent made considerable growth, though not so much as ovaries treated with $\mathrm{K}$-indole acetate. The pyrrole- $\alpha$-acetic acid can then be said to possess some growth activity.

The mechanism of FrUit growth.-Comparison of rate of growth of fruits produced parthenocarpically by indole-acetic acid and its salt and the rate of growth of normally produced fruits.-In order to learn something more about the activity of growth substances in fruit development several experiments were devised, but before these are described, some measurements on comparative growth in fruits pro- 
TABLE 1. Comparative rate of growth of fruits of tobacco produced by injecting the ovaries with $1: 5100 \mathrm{~K}$-indole acetate and by pollination.

Length of fruits in millimeters

Treated with K-indole acetate

\begin{tabular}{|c|c|c|c|c|c|c|c|c|c|}
\hline \multirow[b]{2}{*}{ No. } & \multirow{2}{*}{ Age in days } & \multicolumn{4}{|c|}{ acetate } & & \multicolumn{2}{|c|}{ Pollinated } & \\
\hline & & 3 & 5 & 8 & 21 & 3 & 5 & 8 & 33 (r:pe) \\
\hline 1 & $\ldots \ldots$ & 12 & 14 & 17 & & 9 & 16 & 23 & 23 \\
\hline 2 & $\ldots \ldots \ldots \ldots \ldots$ & 14 & 19 & 23 & & 8 & 14 & 20.5 & \\
\hline 3 & $\ldots \ldots \ldots \ldots \ldots$ & 13 & 18 & 23.5 & & 8 & 15 & 22 & \\
\hline 4 & $\ldots \ldots \ldots \ldots \ldots$ & 12 & 17 & 18 & & 10 & 15 & 21 & 22 \\
\hline 5 & $\ldots \ldots \ldots \ldots \ldots$ & 11 & 16 & 18 & & 15 & 17 & 21 & 19 \\
\hline 6 & $\ldots \ldots \ldots \ldots \ldots$ & 14 & 20 & 24 & 24 & - & $\ldots$ & $\longrightarrow$ & - \\
\hline 7 & $\ldots \ldots \ldots \ldots \ldots$ & 13 & 15 & 20 & & Ave. 10.0 & 15.4 & 21.3 & 21.33 \\
\hline 8 & $\ldots \ldots \ldots \ldots \ldots$ & 12 & 16 & 20.5 & & & & & \\
\hline 9 & $\ldots \ldots \ldots \ldots \ldots$ & 12 & 16 & 20 & & & & & \\
\hline 10 & $\ldots \ldots \ldots \ldots \ldots$ & 15 & 17 & 20 & & & & & \\
\hline 11 & $\ldots \ldots \ldots \ldots \ldots$ & 13 & 18 & 21 & & & & & \\
\hline 12 & $\ldots \ldots \ldots \ldots \ldots$ & 16 & 19.5 & 22.0 & & & & & \\
\hline & Average ...... & 13.0 & 17.1 & 20.6 & & & & & \\
\hline
\end{tabular}

TABLE 2. Comparalive rate of growth of fruits of tobacco produced by injecting the ovaries with 1:1000 indole-acetic acid and by pollination.

Length of fruits in millimeters

Treated with indoleacetic acid Pollinated

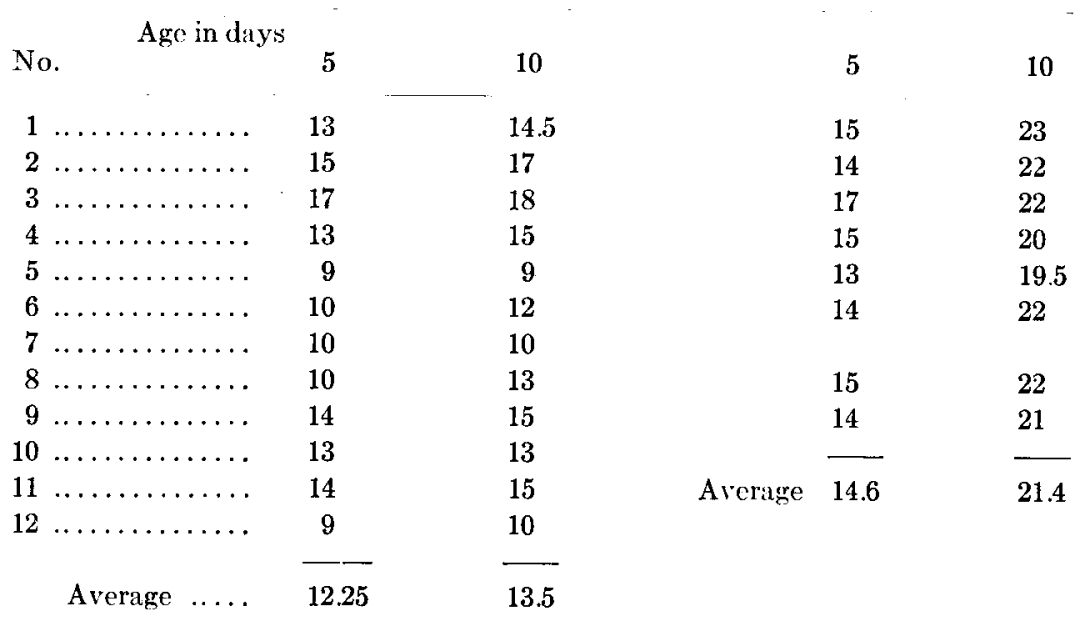

duced parthenocarpically and fruits produced as a not mature, they were, nevertheless, nearly full grown. result of pollination and fertilization will be noted. The ovaries injected with indole-acetic acid were not

The two tables demonstrate that during the first few days of development the ovaries treated with $\mathrm{K}$-indole acetate grew faster than the pollinated ones, but on the 8th day the latter were growing more rapidly, and the final size was somewhat larger. The average size of 13 ripe fruits produced by pollination gave a measurement of $21.37 \mathrm{~mm}$. in length, while the 12 parthenocarpic fruits in table 1 were only $20.6 \mathrm{~mm}$. in length. Although these latter fruits were measured until they were 5 days old, and at that time they were smaller than the naturally produced fruits, and by the time they were 10 days old this difference was much greater. The fruits produced by indole-acetic acid treatment were always smaller than those produced by pollination and $\mathrm{K}$-indole acetate treatment.

The fact that the ovaries injected with $\mathrm{K}$-indole acetate grew more rapidly at first than the pollinated 
ones and later grew slower would indicate that at first they had more available growth promoting material while later it became depleted. On the other hand, in the ovaries of the flowers that had been pollinated there was a continuous renewal of the growth substance, supplied either by the developing seeds or by some other part of the ovary. If the parthenocarpically produced fruits could have had their supply of the growth substances continuously renewed, they might have continued to grow as rapidly as they started out to do. Yet when several injections were made there was no more growth than when only one injection was made.

Influence of developing seeds upon fruit growth.To discover the influence of seeds upon the development of an ovary into a fruit, two sets of experiments were set up. In the first experiment it was desired to find out if the act of fertilization and the commencement of seed formation was sufficient to enable the ovary to continue its development into a fruit if the young seeds were removed. Crookneck summer squashes that had been insect-pollinated and had made some growth were cut off in such a way that either no ovules or only a few were left in the ovary. As every one familiar with the crookneck summer squash knows, ovules are located only in the apical end of the ovary. In these experiments either all or many of them might have grown even though they did not contain any ovules nor developing seeds.

The other experiment consisted of reducing the amount of pollination and thus the seed production. Various amounts of the lobed stigma were removed from the unpollinated ovaries of pumpkin and crookneck summer squash before pollination. In some experiments as much as five-sixths of the total stigmatic surface was removed before pollen was applied by hand. In these cases the pollination was thus onesided. Most of the ovaries treated in this way developed into fruits. A large reduction in stigmatic surface decreased the number of seeds considerably, but even when this happened the fruits were still normal in size and shape. The application of pollen to one side of the ovary did not limit the development of the seeds to that side, and the seed distribution was quite uniform even when as much as five-sixths of the stigma had been removed. It was perhaps to be expected that a reduction in the number of seeds would not decrease the size of the fruits, as it is a common observation that some years apples contain very few seeds, yet they are no smaller than during those years when they produce many seeds. It was expected, however, that the seeds might develop only on that side of the ovary where the pollen was applied and the side without seeds would

TABLE 3. Influence of grouth-promoling substances upon the development of summer squash fruits, when the ovaries were cut so as to eliminale all ovules.

Treatment

Indole-acetic acid $\ldots \ldots \ldots \ldots . \quad 14$

Indole-butyric acid $\ldots \ldots \ldots \ldots .9$

Pyrrole-acetic acid $\ldots \ldots \ldots \ldots, 12$

Control ................ 6

most of the part containing the ovules was cut off. Forty-six young fruits were thus treated. Of these 41.3 per cent continued to grow after the removal of the apical end, but the average increase in length was only 48.23 per cent. On the other hand, some fruits grew considerably more. In fruit number 22 there was an increase of 143.6 per cent, and the length of the fruit at the time of measurement was $38 \mathrm{~cm}$. Another fruit which increased 62.5 per cent had a length of $46.8 \mathrm{~cm}$., which compares favorably with mature fruits. Forty-one normally produced mature fruits were measured, and the average length was found to be $45.0 \mathrm{~cm}$., but they ranged in length from $26.0 \mathrm{~cm}$. to $70.0 \mathrm{~cm}$. It is to be noted that whenever there was marked growth in these decapitated fruits there were a considerable number of ovules present, which were developing into seeds. Though developing seeds seem to be favorable or even necessary to the continued elongation of the fruit, the evidence is not entirely convincing because so many ovaries were destroyed by fungi. It is possible that had these fruits not been attacked by fungi

\begin{tabular}{ccc} 
\% that grew & $\begin{array}{c}\text { \% increase } \\
\text { in length }\end{array}$ & $\begin{array}{c}\text { \% increase } \\
\text { in diameter }\end{array}$ \\
71.43 & 198.02 & 204.79 \\
77.78 & 90.55 & 132.16 \\
8.2 & 83.33 & \\
0 & 0 & \\
\hline
\end{tabular}

be apertrophied. There was little, if any, evidence of this. It thus becomes evident that the presence of even a few seeds enables the ovary to make a normal amount of growth, while without any seeds there is little or no growth of the ovary in the crookneck summer squash and none in the pumpkin.

Influence of ovules upon the growth of fruits.-In another series of experiments ovaries from unopened crookneck summer squash flower buds were cut off in a manner similar to that above and the cut surface smeared with 5 per cent indole-butyric acid paste. Of 9 ovaries treated 7 showed some enlargement. The average increase in length was 397.13 per cent, and the fruit on the right in figure 6 grew to a length of $44.0 \mathrm{~cm}$. When these ovaries were treated, no care was taken to exclude all of the ovules, and in several, like the one pictured in figure 6 , there were some ovules present, though they did not develop into seeds.

We have no direct evidence that the ovules increase the growth of either the ovary or the fruit, though Katunskij (1936) associates the ovule development 
with a high production of auxin in the plant and states that the pre- and post-floral movements of peduncles and scapes of some plants is due to the presence of a large quantity of auxin in the plant, and this auxin he reports is produced in the ovules.

Induction of growth of ovuleless portions of ovaries by growth-promoting compounds.-In further experiments care was taken to exclude all ovules from the remainder of the ovary. In most instances this left about one-third of the original ovary, or a piece about 2 to $3 \mathrm{~cm}$. long and less than one centimeter in diameter. These decapitated ovaries were treated with indole-acetic, indole-butyric, pyrrole-acetic, or pure lanolin. The results of these experiments are given in table 3 and figures 6 and 7 .

As the figures and the table show, decapitated ovaries without ovules grew considerably both in length and diameter. The ovule-bearing part having bcen removed, there was no special enlargement at the apex, and the "fruits" grew with a uniform cliameter throughout their whole length. Comparing the percentage increase in growth of ovaries from which all ovules had been removed (when treated with indole-butyric acid) with those in which some ovules were retained, it appears that the presence of the ovules brought about an increased growth beyond that produced as a result of the presence of the indole-butyric acid.

Discussion. - While there is no intention of indulging in a general discussion of growth hormone activity, it may be permissible to draw attention to certain facts that have a broader application than to that of parthenocarpy alone. The experiments with the potassium salt of indole-acetic acid corroborate other recent investigations in showing that the acid is not necessary and that at least the potassium salt of indole-acetic acid is very active even though it may turn out to be less active than the acid itself. This has no bearing on the controversy as to the active form of the growth substance in the cell. It is sometimes very convenient to use the salt instead of the acid, as the former is more soluble. Tables 1 and 2 show that the tobacco fruits produced as a result of treatment with the $\mathrm{K}$-indole acetate grew larger than those produced by the acid. This difference in size may be due to the greater concentration of the salt used. The acid was made up to 0.1 per cent, but after standing for some days there was formed a sediment on the bottom of the container so that the concentration used after the first few days was less than 0.1 per cent, and 0.05 per cent solution had previously been found to be too dilute. Therefore the 0.2 per cent solution of the salt gave the plant a greater supply upon which to draw as the fruit continued to develop. As pointed out before, it is highly probable that the reason the tobacco responded so well was that the solution which went into the sepals acted as a reserve.

While the pyrrole compounds are not so active as the corresponding indole compounds, it is perfectly clear that the phenyl group of the indole radicle is not necessary for the growth promoting activity of indole compounds. The activity of the phenyl group in phenylacetic acid is of course well known, but phenylacetic acid is much less active than indole acetic acid. It is thus seen that the two rings making up the indole radicle possess activity when combined alone with acetic acid, but greater activity when together in form of indole acetic acid. It is to be noted that in the pyrrole compounds used the acid is attached in the alpha position, while in the active indole compounds the acid is attached in the beta position. As far as the writer knows, no indole compounds with the acid in the alpha position have been used as growth promoting substances.

Evidently developing seeds even though few in numbers exert an important influence upon the growth of a fruit. It seems that even ovules without embryos increase the growth of the ovary. Yet ovaries of crookneck summer squash from which all ovules have been removed will grow if growth substances are applied to them, but not without. From all of which one is almost forced to agree with Dollfus (1936) that the ovules growing into the seeds supply the growth hormone, which causes the ovary to become the fruit. But if that is true, where does the hormone come from that is instrumental in the growth of natural parthenocarpic fruit like seedless oranges, grapefruit, grapes, bananas, cucumbers, and others?

\section{SUMMARY}

Of 13 new chemicals tested $\mathrm{K}$-indole acetate, pyrrole- $\alpha$-carbyxylic, and pyrrole- $\alpha$-acetic acids produced parthenocarpic fruits in several different plants. The potassium salt of indole acetic acid is approximately as effective as the acid. The fact that the pyrrole compounds are active proves that the indole radicle is not necessary for growth promoting activity in the indole compounds. Even when the apical part of a crookneck summer squash is cut off, the basal end, without any ovules, will grow if supplied with growth substances. The presence of ovules seems to give a somewhat better growth, however. Ovaries of crookneck summer squash in which seeds have started to grow will not continue to grow if cut in such a way as to eliminate all the developing seeds.

Department of Botany,

University of Michigan

\section{LITERATURE CITED}

Avery. G. S., P. R. Burkholder, and H. B. Creighton. 1937. Avena coleoptile curvature in relation to different concentrations of certain synthetic substances. Amer. Jour. Bot. 24: 226-232.

Dolcfus, H. 1936. Wuchsstoffstudien. Planta 25: 1-21.
Gustafson, F. G. 1936. Inducement of fruit development by growth-promoting chemicals. Proc. Nat. Acud. Sci. 22 : 628-638.

- - 1937. Parthenocarpy induced by pollen extracts. Amer. Jour. Bot. 24: 102-107. 
Katunskis, V. M. 1936. On the cause of pre- and post-natal floral movements of peduncles and scapes (of the genera Papaver, Crepis, and Tussilago). Compt. Rend. (Doklady) Acad. Sci. U.S.S.R. 3: 343-346.

McCay, C. M., and C. L. A. Schmidt. 1926. Observations upon the synthesis of pyrrole- and pyrrolidonecarboxylic acids, and upon the synthesis of alphathionic acid of pyrrole. Jour. Amer. Chem. Soc. 48: 1933-39.

Nenitzescu, C. D., and E. Solomonica. 1931. Utber d:e Einwirkung von aliphatischen Diazoverbindungen auf Pyrrol und seine Homologen. Ber Deutsch. Chem. Ges. 64: 1924-31.

Went, F. W., and K. V. Thimann. 1937. Phytohormones. New York.

YASUDA, S. 1934. The second report on the behavior of the pollen tubes in the production of seedless fruits caused by interspecific pollination. Japan. Jour. Gen. 9: 118-124.

Zimmerman, P. W., and A. E. Hitchoock. 1937. Comparative effectiveness of acids, esters, and salts as growth substances and methods of evaluating them. Contrib. Boyce Thompson Inst. 8: 337-350.

\section{STRAND FORMATION IN PHYMATOTRICHUM OMNIVORUM ${ }^{1}$}

\section{H. Rogers and G. M. Watkins}

There has been some discussion in the literature concerning the role of the mycelial strands of Phymatotrichum omnivorum (Shear) Duggar in the parasitic action of the fungus. The writers have had opportunity during the last few years to observe the formation of strands under various conditions and believe that an account of the process will be of value in this connection. A brief report of the method of strand formation has been made by Rogers (1932, 1933). The observations presented here relate to the production of strands on the surface of roots of fieldinfected cotton plants, among the superficial hyphae in pure cultures, and among the network of hyphae produced upon resumption of growth by sclerotia placed in moist chambers.

Methods.-For the purpose of obtaining information on the time relations in strand formation, a number of Petri dishes containing sterile potatodextrose agar were inoculated with small masses of hyphae of $P$. omnivorum and incubated at room temperature for one month. During this time the growth of the colonies was observed regularly; at intervals a few of the plates were opened and representative samples of mycelium were removed and mounted in lactophenol for study. A series of drawings was prepared to illustrate early stages in strand formation as shown in these mounts (fig. 5-11).

Small moist chambers were used for observing strand development among the actively growing mycelium which arises from sclerotia and agar blocks containing hyphae. These chambers were prepared by cementing four narrow strips of plate glass onefourth inch thick in the form of a rectangle upon a thin sheet of clear glass. Canada balsam served as an efficient cement for this murpose. Each of the several cells thus constructed had inside dimensions of approximately two inches by three inches by onēfourth inch and could be sterilized to guard a gainst contamination. Surface-sterilized sclerotia which had been excavated from infested fields were placed in some of these chambers; in others agar blocks con-

${ }^{1}$ Received for publication January 24, 1938.

Published with the approval of the Director as contribution No. 441, Technical Series, of the Texas Agricultural Experiment Station. taining hyphae were used as inoculum. After insertion of the sclerotium or agar block in each case the chamber was covered by means of a thin glass cover and sealed around the edges with paraffin. The hypha which developed from the inoculum in each chamber grew over the surface of the glass bottom, were observed from day to day, and were photographed at intervals (fig. 1-4).

Observations.--In Petri dish cultures the fungus covers the area of the plate during the first week after inoculation with the typically radiating branchsystems of hyaline, superficial and subsurface mycelium. Each such branch-system is composed of a large central hypha ranging in diameter from $15 \mu$ to $40 \mu$, with septa at irregular intervals and repeatedly branching lateral hyphae of progressively smaller size. Many of the large hyphae have somewhat thickened walls; in such cases the transverse walls are usually not uniform in thickness, but take the form of a plate of gradually increasing thickness from the center toward the line of junction with the longitudinal wall (fig. 8, 9). In later stages these peripheral thickenings separate centripetally for a short distance and bring about a slight elongation of the hyphae (fig. 10).

The beginning of the compounding of hyphae into strands can be observed in cultures five to ten days old, depending upon environmental conditions, such as type of substratum, moisture, and temperature. Within a branch-system some of the adjacent small hyphae make contact with the central hypha (fig. 2, $3,5,6,10)$. In either case abundant branching of the small hyphae occurs, with the result that the central hypha is covered with an irregular network of interwoven filaments of much smaller diameter. It should be noted that the agglomeration of small hyphae does not ordinarily proceed uniformly along all parts of the central hypha, but begins with the formation of knots at irregular intervals (fig. 1, 3). From these original knots the compounding of hyphae tends to progress longitudinally until the central hypha is covered at all points. In the formation of a layer the encircling hyphae at first appear as a tangled mass of threards. Later, however, through adjustment of positions and the production of numer- 